\title{
Gallbladder adenocarcinoma with sarcoid-like reaction in regional lymph nodes: report of a case
}

\author{
Yota Kawasaki, Kosei Maemura, Hiroshi Kurahara, Yuko Mataki, Satoshi lino, Masahiko Sakoda, Shinichi Ueno, \\ Hiroyuki Shinchi, Sonshin Takao and Shoji Natsugoe
}

\begin{abstract}
Background: Sarcoid-like reaction is often seen in various types of carcinoma, not only in the primary tumor, but also in regional lymph nodes, and can occur at any time, not only at the time of diagnosis, but also after treatment. However, few cases of hepatopancreatobiliary carcinoma, and no cases of gallbladder cancer with sarcoid-like reaction involving the lymph nodes have been described. This report is the first report of a sarcoid-like reaction involving the lymph nodes in a case of gallbladder cancer.
\end{abstract}

Case presentation: We encountered a rare case of gall bladder cancer with sarcoid-like reaction in the lymph nodes. Since regional lymph node swelling that was difficult to differentiate from metastasis was found preoperatively, swollen nodes were examined histologically using frozen sections. Based on this histology, the swollen nodes were diagnosed as showing sarcoid reaction and therefore extended lymphadenectomy was avoided. The patient did not receive any adjuvant chemotherapy and has shown no recurrence of disease as of 4 years after surgery.

Conclusion: Distinguishing between metastasis and sarcoid-like reaction in lymph nodes by preoperative imaging is still difficult. The present case shows that it is important to histologically examine swollen nodes by biopsy or by sampling before deciding on the treatment strategy for gall bladder cancer with swollen lymph nodes.

Keywords: Sarcoid-like reaction, Gallbladder cancer, Multiple swollen lymph nodes

\section{Background}

Sarcoid-like reaction is known to occur in patients with malignant disease and can occur at any time, not only at the time of diagnosis, but also after treatment [1]. Sarcoid-like reaction can be found in the stroma of the primary tumor itself, in lymph nodes draining the area of the primary tumor, and even in organs such as the liver, spleen, stomach and lungs [1-3].

Pathologically, sarcoid-like reaction includes noncaseating epithelioid cell granuloma that is comprised of a focal accumulation of epithelioid cells and multinucleated giant cells, and patients with sarcoid-like reaction show no clinical symptoms of systemic sarcoidosis. The non-caseating epithelioid granuloma is a result of antigenspecific cell-mediated immunity caused by macrophages and T-lymphocytes [4]. Although the pathogenesis of sarcoid-like reaction has been reported, no consensus has

\footnotetext{
* Correspondence: gekayota@gmail.com

Department of Digestive Surgery, Breast and Thyroid Surgery, Graduate School of Medical Sciences, Kagoshima University, Sakuragaoka 8-35-1,
} Kagoshima 890-8520, Japan been reached on a complete definition. Sarcoid-like reaction is hypothesized to represent an antineoplastic immune phenomenon caused by antigenic factors derived from the tumor, with the high reactivity of the host immune system against such antigenic factors leading to the development of non-caseating epithelioid granuloma [2,5].

Although many authors have reported sarcoid-like reactions in cancer patients, this finding appears to be very rare in patients with hepatopancreatobiliary cancer [6]. We report herein a rare case of gall bladder cancer with sarcoid reaction in the lymph nodes and no systemic sarcoid phenomenon.

\section{Case presentation}

A 73-year-old Japanese woman was referred to our institution after a gall bladder mass was detected on screening ultrasonography (US).The patient had no complaints, and both physical examination and laboratory findings (including carcinoembryonic antigen, carbohydrate antigen 19-9, and soluble interleukin-2 receptor) were unremarkable. When we performed US, a mass measuring $23 \times 22 \mathrm{~mm}$ 
was identified at the fundus of the gall bladder. This broad-based, sessile mass showed preservation of the outer hyperechoic layer, suggesting gall bladder cancer. According to a previous report, these findings corresponded with a Type B image [7]. Tumor invasion seemed limited to the muscularis propria (cT1b) [7]. Computed tomography (CT) revealed several lymph nodes that were swollen to 7-15 $\mathrm{mm}$, located at both the hepatoduodenal ligament and in the para-aortic area. Diffusion-weighted imaging (DWI) showed a signalhyperintense gallbladder mass, but signal hypointensity for all detected swollen lymph nodes (Figure 1). Based on such findings, the swollen nodes were diagnosed as metastases. As a preoperative summary, we regarded this tumor as clinically stage IIB (cT1b, cN1, cM0) based on the $7^{\text {th }}$ edition of the Union for International Cancer Control (UICC).
Based on the above evidence of gallbladder cancer, we planned to perform radical cholecystectomy involving removal of the gallbladder and extrahepatic biliary tract with en-bloc subsegmental resection of the adjacent hepatic parenchyma of segments $4 \mathrm{~B}$ and 5 , and regional lymphadenectomy involving complete removal of the hepatoduodenal ligament lymph nodes, common hepatic artery nodes and retropancreatic nodes [8]. During surgery, we detected swollen lymph nodes. Four of these lymph nodes were dissected and frozen sections were histologically examined. Unlike typical metastatic lymph nodes, these nodes showed a smooth, round shape with clear margins, and were easy to dissect (Figure 2). Histological frozen-section examination revealed that none of the lymph nodes showed tumor involvement but instead they showed non-caseating epithelioid cell granuloma (Figure 2). We therefore only performed

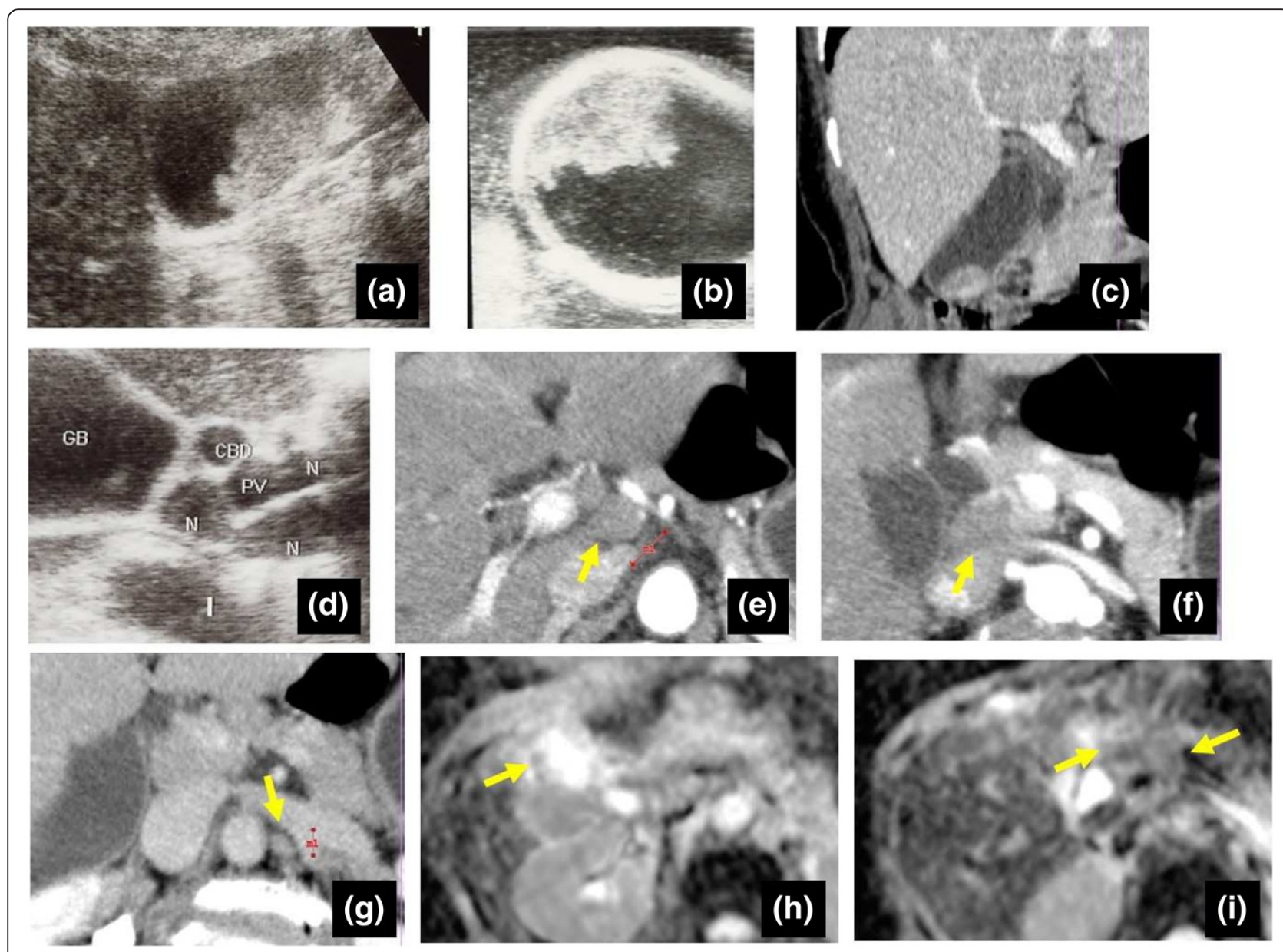

Figure 1 Pre- and intraoperative images. a-c) Ultrasonography (US) shows a highly echoic mass in the gallbladder. The size was $\varphi 30$ mm. The widespread lesion showed irregular, gross progression, corresponding to gallbladder cancer. Because the outer layer of the gallbladder was clearly preserved (especially on intraoperative US), indicating Type B, tumor depth was estimated as extending to the muscularis propria. Computed tomography (CT) also shows a mass in the gallbladder, with no invasion to other organs. d) US shows multiple swollen lymph nodes in the hepatoduodenal ligament. e-g) CT shows swelling of not only lymph nodes at the hepatoduodenal ligament, but also para-aortic lymph nodes. h,i) Diffusion-weighted imaging (DWI) shows signal hyperintensity for the gallbladder mass, but signal hypointensity in all detected swollen lymph nodes. 

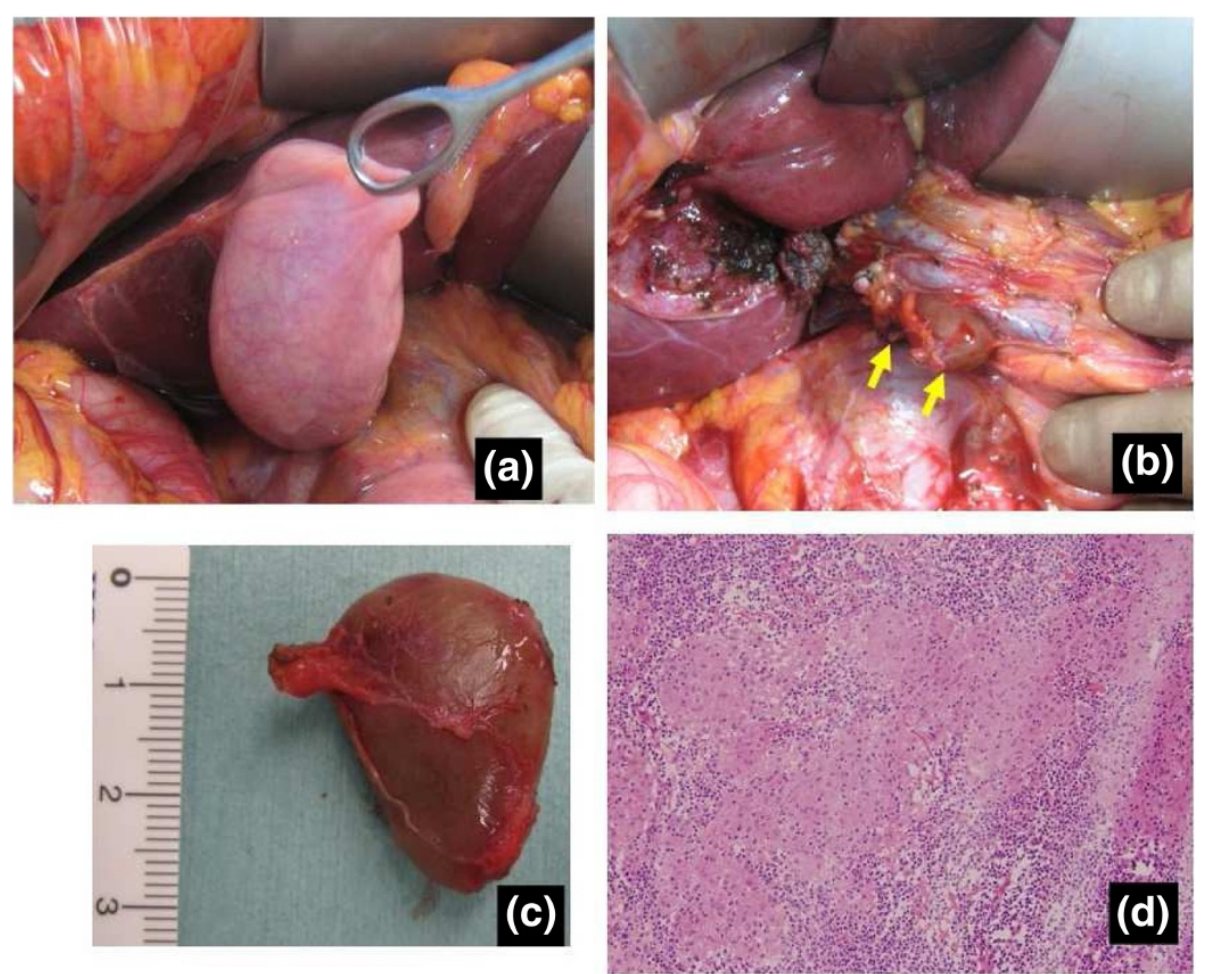

Figure 2 Intraoperative findings. a) Macroscopically, no invasion to the serosa is evident. No shrinkage derived from invasion to the subserosa is seen. $\mathbf{b}, \mathbf{c})$ Swollen lymph nodes are easily dissected out, and the margins are clear. $\mathbf{d}$ ) Frozen-section examination of swollen nodes shows only non-caseating epithelioid cell granuloma.

simple cholecystectomy, and some of the swollen nodes in the hepatoduodenal ligament were not dissected. Histological examination of the resected gall bladder showed papillary carcinoma with invasion limited to the muscularis propria. None of the dissected lymph nodes showed tumor involvement and all were diagnosed as showing non-caseating epithelioid cell granuloma. Accordingly, the patient was diagnosed with papillary adenocarcinoma of the gall bladder, stage IA (pT1b, pN0, pM0) (Figure 3). Because of the early stage of gall bladder cancer, adjuvant chemotherapy was not performed. As of 4 years postoperatively, the patient has shown no disease recurrence. During follow-up examination, the size of swollen nodes remaining in the hepatoduodenal ligament has gradually decreased compared to the initial size at the time of surgery (Figure 4).

\section{Discussion}

Sarcoid-like reaction related to a tumor was first reported in the early $19^{\text {th }}$ Century [5]. Since then, such reactions have been reported with various carcinomas, such as those of the stomach, lungs, uterus and breast $[3,9,10]$. Brincker et al. [5] reported that sarcoid-like reactions may occur in $4.4 \%$ of cancer patients, $13.8 \%$ of patients with Hodgkin's disease, and $7.3 \%$ of patients with non-Hodgkin lymphoma. In cases of carcinoma, sarcoid-like reaction is found in regional lymph nodes, particularly in non-metastatic lymph nodes. Few cases of hepatopancreatobiliary carcinoma with sarcoid-like reaction involving the lymph nodes have been described. Fong et al. [6] summarized 15 cases of hepatopancreatobiliary tumor with sarcoid-like reaction in 2012. However, only 19 cases in total have been reported to date (Table 1), and there have been no reports regarding sarcoid-like reaction in gallbladder cancer.

Gallbladder cancer is the most common malignant neoplasm of biliary tract cancer, and unfortunately the prognosis is well known to be very poor [25]. In many cases, gall bladder cancer is already at an advanced stage by the time of detection and diagnosis [8]. Lymph node metastasis is an important prognostic factor for this tumor, as it is for other malignant tumors. Preoperative diagnosis of the presence or absence of nodal metastasis is thus important when planning a surgical strategy. In the case of node positive gallbladder cancer (except for positive para-aortic lymph nodes), although there is certainly some controversy, it is considered that "aggressive" radical surgery such as combined resection 

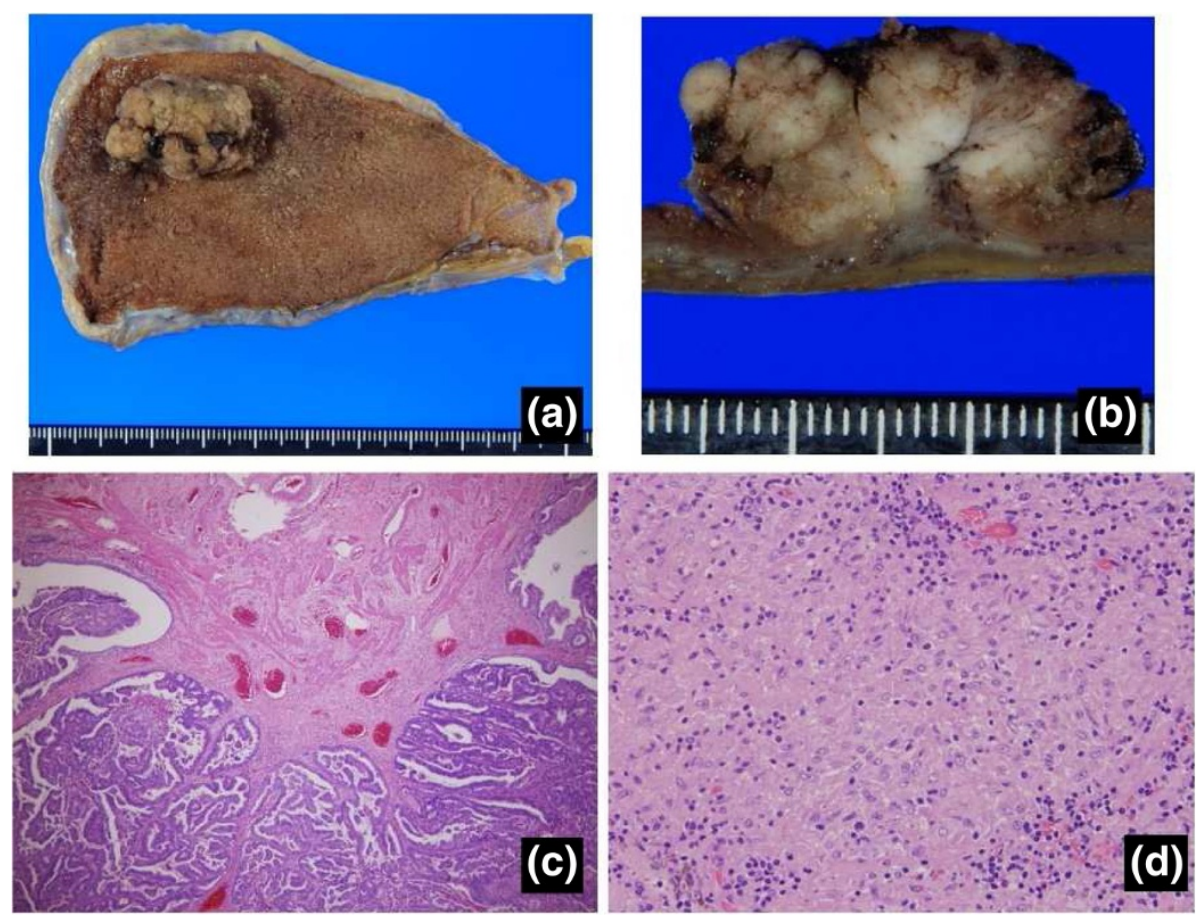

Figure 3 Macro- and microscopic findings. a) Macroscopic appearance of the gall bladder mass located in the fundus. b) Tumor infiltration to the muscularis layer is evident macroscopically. c) Tumor infiltration to the muscularis propria is evident microscopically. d) Final pathological examination of swollen lymph nodes shows only non-caseating epithelioid cell granuloma, with no evidence of metastasis in any dissected lymph node.

of the liver and the common bile duct together with extended lymphadenectomy might contribute to better prognosis [26,27]. In the present case, we preoperatively diagnosed multiple nodal swellings observed by imaging as positive evidence of metastasis. Distinct radiographic patterns that can distinguish sarcoid-like reaction, sarcoidosis and carcinoma have not yet been identified [1]. If the differential diagnosis of lymph node swelling is difficult, intraoperative histological examination of frozen sections is essential. In this case, we were able to avoid extended lymphadenectomy, because the histological results showed a sarcoid-like reaction. Some authors have reported that preoperative biopsy through endoscopic ultrasoundguided-fine needle aspiration (EUS-FNA) may represent a useful method for analysis of such nodes [1,28,29].

The medical records of this patient included no symptoms or signs related to systemic sarcoidosis, such as erythema nodosum, uveitis, acute polyarthritis, respiratory
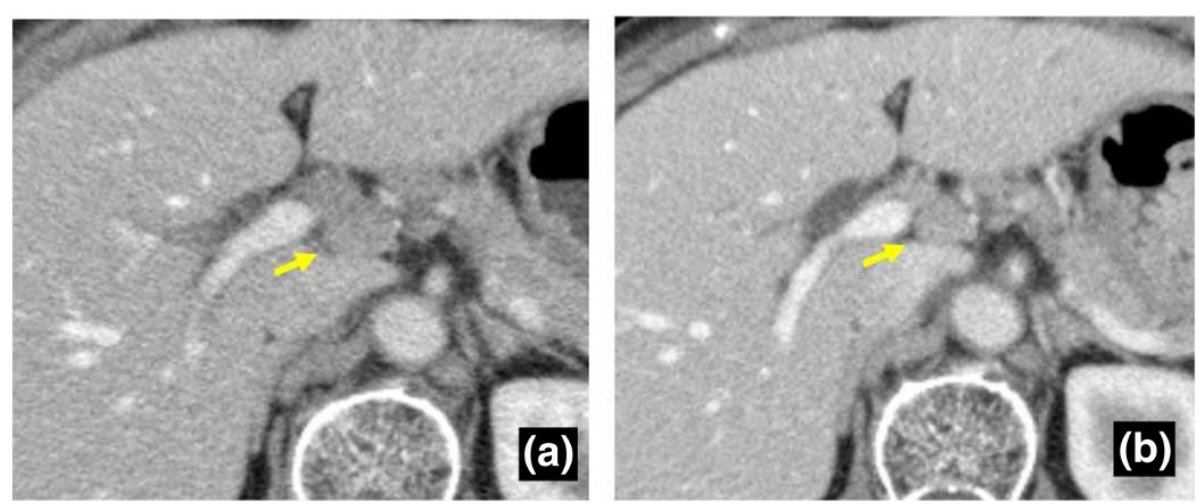

Figure 4 Course of remaining swollen lymph nodes. a) CT 5 months after surgery shows a remaining swollen lymph node (No. 12). The size is $15 \times 11 \mathrm{~mm}$. b) CT 46 months after surgery also shows the remaining swollen No. 12 lymph node. The size $(11 \times 8 \mathrm{~mm})$ appears to be reduced compared to the initial examination. 
Table 1 Reports of sarcoid-like reactions in patients with hepatopancreatobiliary malignancy

\begin{tabular}{|c|c|c|c|c|c|c|}
\hline Author & $\begin{array}{l}\text { Year } \\
\text { published }\end{array}$ & Journal & Age & Sex & Primary disease & Location of sarcoid reaction \\
\hline Herxheimer G [1 1] & 1917 & Z Tuberk & N/A & N/A & Cholangiocarcinoma & Liver \\
\hline Gherardi G [12] & 1950 & Arch Pathol & 61 & $\mathrm{~F}$ & Cholangiocarcinoma & Peri-hepatic LN \\
\hline Nadel EM [13] & 1950 & Am J Clin Pathol & 64 & M & Ampullary adenocarcinoma & Peri-pancreatic LN \\
\hline Ten Seldam RE [14] & 1956 & Med J Australia & N/A & N/A & Cholangiocarcinoma & Lesser Omental LN \\
\hline Muto Y [15] & 1982 & Jpn J Gastroenterol Surg & 62 & $\mathrm{~F}$ & Cholangiocarcinoma & Hilar and pericystic LN \\
\hline Schmidt D [16] & 1985 & $\begin{array}{l}\text { Virchow Arch A Othhol } \\
\text { Anat Hitopathol }\end{array}$ & N/A & N/A & Hepatoblastoma & Liver \\
\hline Schmidt D [16] & 1985 & $\begin{array}{l}\text { Virchow Arch A Othhol } \\
\text { Anat Hitopathol }\end{array}$ & $\mathrm{N} / \mathrm{A}$ & N/A & $\mathrm{HCC}$ & Liver \\
\hline Van Steenbergen W [17] & 1987 & J Clin Gastroenterol & 30 & M & Cholangiocarcinoma & Liver and Hilar LN \\
\hline Klein M [18] & 1994 & Chest & 61 & M & Cholangiocarcinoma & Hilar and paratracheal LN \\
\hline Nakao A [19] & 1996 & Biliary Tract Pancreas & 69 & $\mathrm{~F}$ & Cholangiocarcinoma & Peri-ductal LN \\
\hline Shito M [20] & 1997 & Jpn J Surg & 69 & $\mathrm{~F}$ & Cholangiocarcinoma & Peri-ductal LN \\
\hline Onitsuka A [21] & 2003 & J Hepatobiliary Pancreat Surg & 74 & $\mathrm{~F}$ & Cholangiocarcinoma & Peri-ductal LN \\
\hline Mao JT [22] & 2000 & Am J Med & 71 & M & PDA & Lung \\
\hline Kurata A [23] & 2005 & Hum Pathol & 44 & M & PDA & Peri-pancreatic LN \\
\hline Kurata A [23] & 2005 & Hum Pathol & 60 & M & PDA & Peri-pancreatic LN \\
\hline Chowdhury FU [2] & 2009 & Clin Radiology & 62 & M & PDA & Sub-pleural LN \\
\hline Fong ZV [6] & 2012 & J Gastrointest Surg & 59 & $\mathrm{~F}$ & Cholangiocarcinoma & Spleen \\
\hline Fong ZV [6] & 2012 & J Gastrointest Surg & 68 & $\mathrm{~F}$ & IPMN & liver and bone \\
\hline Mastroroberto M [24] & 2012 & Journal of the pancreas & 52 & M & NET, pancreas & Hilar and paratracheal LN \\
\hline
\end{tabular}

PDA: pancreatic adenocarcinoma, IPMN: intraductal papillary mucinous neoplasm, NET: neuroendcrine tumor F: female, M: male, LN: lymph node.

illness, fatigue, malaise, weight loss or fever [30]. Moreover, no serum abnormalities such as hypercalcemia or elevated levels of angiotensin-converting enzyme were seen. Accordingly, we speculate that the development of non-caseating epithelioid cell granuloma in this patient was not caused by systemic sarcoidosis, but rather by a sarcoid-like reaction related to gallbladder cancer. Sarcoid-like reactions are comprised of different inflammatory cells, mature dendritic cells and T lymphocytes in non-caseating epithelioid cell granulomas [23]. Infiltration of tumors by dendritic cells reflects a host immune defense mechanism [31]. It is well known that the presence of dendritic cells and $\mathrm{T}$ lymphocytes in tumors is associated with better prognosis, reduced tumor recurrence and fewer metastases [32-36]. Although no consensus has been reached, these evidences seem to suggest that patients with a malignant tumor that shows a sarcoid-like reaction may have a better prognosis [37]. Indeed, our patient has shown long-term survival and no recurrence after surgery.

Few reports have focused on the course of swollen nodes after resection of a primary cancer. Interestingly, in this case, the residual swollen nodes gradually decreased in size after resection of the gallbladder cancer. This phenomenon clinically supports the view that sarcoid-like reaction results from high reactivity of the host immune system against antigenic factors from the primary cancer.

\section{Conclusion}

We encountered a case of sarcoid-like reaction related to gallbladder cancer. Distinguishing between metastasis and sarcoid-like reaction in lymph nodes by preoperative imaging is still difficult. The present case shows that it is important to histologically examine swollen nodes by biopsy or sampling before deciding on the treatment strategy for gall bladder cancer with swollen lymph nodes.

\section{Consent}

Written informed consent was obtained from the patient for publication of this Case report and any accompanying images. A copy of this written consent is available for review by the Editor-in-Chief of this journal. This study was approved by the institutional ethics review board of Kagoshima University Hospital (reference number 25-39).

\section{Abbreviations}

US: Ultrasonography; CT: Computed tomography CT; DWI: Diffusionweighted imaging DWI; UICC: Union for International Cancer Control; EUS-FNA: Endoscopic ultrasound-guided-fine needle aspiration. 


\section{Competing interests}

The authors declare that they have no competing interests.

\section{Authors' contributions}

YK performed the surgery, participated in the conception, coordinated with other doctors about the design of the study, collected data and a consent, carried out the histological evaluation and drafted the manuscript. KM participated in the surgery, histological evaluation and in drafting the manuscript. HK, YM and HS participated in the surgery and histological evaluation. SI, MS, SU, ST and SN conceived of the study, participated in its design and coordination and helped to draft the manuscript. All authors read and approved the final manuscript.

\section{Acknowledgements}

We declare that each author received no funding for this study.

Received: 18 August 2014 Accepted: 6 December 2014

Published: 13 December 2014

\section{References}

1. Craun JB, Banks KP, Clemenshaw MN, Moren RW: Sarcoidlike reaction of neoplasia causing hypermetabolic thoracic adenopathy in setting of extrathoracic malignancy: report of two cases and a review of the differential diagnostic considerations. J Nucl Med Technol 2012, 40(4):231-235.

2. Chowdhury FU, Sheerin F, Bradley KM, Gleeson FV: Sarcoid-like reaction to malignancy on whole-body integrated (18)F-FDG PET/CT: prevalence and disease pattern. Clin Radiol 2009, 64(7):675-681.

3. Murata Y, Tachibana T: Sarcoid reactions in malignant tumor. Kekkaku: Tuberculosis 1979, 54(10):510-511.

4. Sugiyama Y, Oshikawa K: Mechanism of sarcoid granuloma formationparticipation of cytokines and chemokines. Nihon Rinsho 2002, 60(9):1728-1733.

5. Brincker H: Sarcoid reactions in malignant tumours. Cancer Treat Rev 1986, 13(3):147-156

6. Fong ZV, Wong J, Maley WR, Sandorfi N, Winter JM, Koniaris LG, Sauter PK, Yeo CJ, Lavu H: Sarcoid-reaction mimicking metastatic malignant hepatopancreatobiliary tumors: report of two cases and review of the literature. J Gastrointest Surg 2012, 16(6):1245-1250.

7. Sadamoto Y, Kubo H, Harada N, Tanaka M, Eguchi T, Nawata H: Preoperative diagnosis and staging of gallbladder carcinoma by EUS. Gastrointest EndosC 2003, 58(4):536-541.

8. Reid KM, Ramos-De la Medina A, Donohue JH: Diagnosis and surgical management of gallbladder cancer: a review. J Gastroint Surg 2007, 11(5):671-681

9. Gregorie HB Jr, Othersen HB Jr, Moore MP Jr: The significance of sarcoidlike lesions in association with malignant neoplasms. Am J Surg 1962, 104:577-586.

10. Kamiyoshihara M, Hirai T, Kawashima O, Ishikawa S, Morishita Y: Sarcoid reactions in primary pulmonary carcinoma: report of seven cases. Oncol Rep 1998, 5(1):177-180.

11. Herxheimer G: Uber Karzinom und Tuberkulose. Z Tuberk 1917, 27:251.

12. Gherardi G: Localized lymph node sarcoidosis associated with carcinoma of the bile ducts; report of a case. AMA Arch Pathol 1950, 49(2):163-168.

13. Nadel E: Lesions resembling Boeck's sarcoid in lymph nodes draining an area containing a malignant neoplasm. Am J Clin Pathol 1950, 20(10):952-957.

14. Ten Seldam R: Sarcoid-like lesions in lymph nodes draining carcinoma. Med Aust 1956, 43(22):916-919.

15. Muto $Y$, Uchimira M, Waki S, Hayashi T, Sameshima Y, Okamoto K: A case of common duct carcinoma with sarcoid reaction in the regional lymph nodes. Jpn J Gastroenterol Surg 1982, 15:512-515.

16. Schmidt D, Harms D, Lang W: Primary malignant hepatic tumours in childhood. Virchows Arch A Pathol Anat Histopathol 1985, 407(4):387-405.

17. Van Steenbergen W, Fevery J, Vandenbrande P, Desmet V, Ponette E, Kerremans $\mathrm{R}$, de Groote J: Ulcerative colitis, primary sclerosing cholangitis, bile duct carcinoma, and generalized sarcoidosis. Report of a unique association. J Clin Gastroenterol 1987, 9(5):574-579.

18. Klein M, Kaminsky P, Deibener J, Cocciale MP, Duc M: Sarcoid reactions in cystic duct carcinoma. Chest 1994, 106(4):1304-1305.
19. Nakao A, Sato Y, Nakashima A: A case of bile duct cancer with sarcoid reaction in the regional lymph nodes. Biliary Tract Pancreas 1996, 17:963-966.

20. Shito M, Shintoku J, Miyazaki H: Primary caricnoma of the cystic duct associated with sarcoid reactions: report of a case. Surg Today 1997, 27:1177-1181.

21. Onitsuka A, Katagiri Y, Kiyama S, Mimoto H, Nakamura T, Toda K, Shima H: Hilar cholangiocarcinoma associated with sarcoid reaction in the regional lymph nodes. J Hepatobiliary Pancreat Surg 2003, 10(4):316-320.

22. Mao JT, Fisnbein MC: Metastatic pancreatic cancer masquerading as pulmonary sarcoidosis. Am J Med 2000, 109(7):598-599.

23. Kurata A, Terado Y, Schulz A, Fujioka Y, Franke FE: Inflammatory cells in the formation of tumor-related sarcoid reactions. Hum Pathol 2005, 36(5):546-554.

24. Mastroroberto M, Berardi S, Fraticelli L, Pianta P, Ercolani G, Cancellieri A, Sama C: Sarcoidosis and sarcoid-like reaction associated with pancreatic malignancy: are you able to read a riddle? JOP 2012, 13(4):454-457.

25. Carriaga MT, Henson DE: Liver, gallbladder, extrahepatic bile ducts, and pancreas. Cancer 1995, 75(1 Suppl):171-190.

26. Foster JM, Hoshi H, Gibbs JF, Iyer R, Javle M, Chu Q, Kuvshinoff B: Gallbladder cancer: defining the indications for primary radical resection and radical re-resection. Ann Surg Oncol 2007, 14(2):833-840.

27. Kondo S, Nimura Y, Hayakawa N, Kamiya J, Nagino M, Uesaka K: Regional and para-aortic lymphadenectomy in radical surgery for advanced gallbladder carcinoma. Br J Surg 2000, 87(4):418-422.

28. Wallace MB, Kennedy T, Durkalski V, Eloubeidi MA, Etamad R, Matsuda K, Lewin D, Van Velse A, Hennesey W, Hawes RH, Hoffman BJ: Randomized controlled trial of EUS-guided fine needle aspiration techniques for the detection of malignant lymphadenopathy. Gastrointest Endosc 2001, 54(4):441-447.

29. Williams DB, Sahai AV, Aabakken L, Penman ID, van Velse A, Webb J, Wilson M, Hoffman BJ, Hawes RH: Endoscopic ultrasound guided fine needle aspiration biopsy: a large single centre experience. Gut 1999, 44(5):720-726.

30. Hunsaker AR, Munden RF, Pugatch RD, Mentzer SJ: Sarcoidlike reaction in patients with malignancy. Radiology 1996, 200(1):255-261.

31. Banchereau J, Steinman RM: Dendritic cells and the control of immunity. Nature 1998, 392(6673):245-252.

32. Zhang L, Conejo-Garcia JR, Katsaros D, Gimotty PA, Massobrio M, Regnani G, Makrigiannakis A, Gray H, Schlienger K, Liebman MN, Rubin SC, Coukos G: Intratumoral T cells, recurrence, and survival in epithelial ovarian cancer. N Engl J Med 2003, 348(3):203-213.

33. Tsujitani S, Kakeji Y, Watanabe A, Kohnoe S, Maehara Y, Sugimaghi K: Infiltration of S-100 protein positive dendritic cells and peritoneal recurrence in advanced gastric cancer. Int Surg 1992, 77(4):238-241.

34. Iwamoto M, Shinohara H, Miyamoto A, Okuzawa M, Mabuchi H, Nohara T, Gon G, Toyoda M, Tanigawa N: Prognostic value of tumor-infiltrating dendritic cells expressing CD83 in human breast carcinomas. Int J Cancer 2003, 104(1):92-97.

35. Ishigami $S$, Aikou T, Natsugoe $S$, Hokita S, Iwashige H, Tokushige M, Sonoda S: Prognostic value of HLA-DR expression and dendritic cell infiltration in gastric cancer. Oncology 1998, 55(1):65-69.

36. Inoue K, Furihata M, Ohtsuki Y, Fujita Y: Distribution of S-100 proteinpositive dendritic cells and expression of HLA-DR antigen in transitional cell carcinoma of the urinary bladder in relation to tumour progression and prognosis. Virchows Arch A Pathol Anat Histopathol 1993, 422(5):351-355.

37. Yamamoto T, Tateishi H, Nishimura Y, Watanabe M, Ukyo S, Miyake T, Uchino H, Matsumoto Y, Ishii K, Takahashi K: A study of gastric cancer with sarcoid reaction as observed in the regional lymph node. Nihon Shokakibyo Gakkai Zasshi 1980, 77(10):1555-1561.

\section{doi:10.1186/1471-2407-14-946}

Cite this article as: Kawasaki et al.: Gallbladder adenocarcinoma with sarcoid-like reaction in regional lymph nodes: report of a case. BMC Cancer 2014 14:946. 